\title{
Las "Pajaritas de papel” de Jaime Campmany (1966-1970): aportación al periodismo literario español
}

\section{"Pajaritas de papel" by Jaime Campmany: a contribution to Spanish literary journalism}

Antonio Fernández Jiménez. Universidad de Murcia (antonio9922_8@hotmail.com)

Recibido: 07/03/2017 - Aceptado: 06/04/2017

\section{Resumen:}

Este artículo da a conocer a grandes rasgos la primera etapa de Jaime Campmany en el ejercicio de la columna periodística a través de la escritura de unos artículos literarios que su autor llamó 'Pajaritas de papel', publicados diariamente en Arriba entre 1966 y 1970. De gran calidad literaria y enmarcadas en una época en que se gestaba un nuevo periodismo, las 'Pajaritas' constituyen una clara contribución al estudio del periodismo literario de finales de la posguerra española por cuanto pudo expresar Campmany en un tiempo en el que todavía la prensa sufría las trabas de la censura. Por ello y además, podemos considerarlas como un precedente preclaro al apogeo de la columna de opinión en las décadas sucesivas.

Palabras clave:

Jaime Campmany; periodismo literario; columna periodística; historia del periodismo español; libertad de expresión.

\section{Abstract:}

The purpose of this article is to give the reader an overview of Jaime Campmany's early career as a columnist who wrote literary articles he called 'Pajaritas de papel' (folded papers birds), which were published daily in the newspaper Arriba from 1966 to 1970. Due to the excellent quality of his literary writings within the framework of a new type of journalism being developed at the time, 'Pajaritas de papel' made a clear contribution to the study of literary journalism near the end of the post-war period in Spain due to his ability to reveal information in his articles at a time when the press was still suffering the impediment of censorship. For that reason and more, we consider his articles to have set a valuable precedent for the exalted status that opinion columns achieved in the decades that followed.

Keywords:

Jaime Campmany; literary journalism; opinion column; history of Spanish journalism; freedom of speech. 


\section{Introducción}

Aunque la biografía periodística de Jaime Campmany (Murcia, 1925-Madrid, 2005) es amplia y variada, su faceta más popular resulta ser la del columnista de $A B C$, desde los años de la Transición española hasta la fecha de su fallecimiento; etapa que, por otro lado, también suele ser la más estudiada. Sin embargo, entre 1966 y 1970, hallamos un valioso período creativo de Campmany que no ha sido investigado hasta ahora y que trata del momento en que el periodista se inicia como articulista diario con unas piezas de gran calidad literaria publicadas en el diario Arriba, bautizadas como 'Pajaritas de papel'.

Como el género periodístico de la columna ha tenido varias manifestaciones en las manos de Campmany, "si tuviéramos que señalar dos épocas notables de esta dedicación (...) tendríamos que referirnos a las que protagonizó su 'Pajarita de Papel' en el diario Arriba en los años ingratos del franquismo y la que ha estado cultivando en el diario $A B C$ " (Cantavella, 2011: 78). En este artículo -que procede de una investigación más amplia sobre el periodismo literario de Campmany-nos centraremos en la época de las 'Pajaritas', que hasta ahora no había sido tratada desde el ámbito académico.

De modo que el objetivo del presente artículo es desentrañar y dar a conocer el período del periodismo literario de Campmany de finales de los años sesenta del pasado siglo. Además, el hecho de contribuir al estudio de las relaciones entre el Periodismo y la Literatura con estos textos que llevaban sin reproducirse desde la época en que se publicaron supone ya una aportación valiosa. El carácter atemporal que adquieren las 'Pajaritas' por el hecho de estar escritas con expresión literaria, puede sernos útil para la compresión de ese momento de la historia de España, con la deleitosa añadidura que supone el leerlas.

Esta investigación también pretende situar a las 'Pajaritas' como un fenómeno plausible y audaz de periodismo de opinión en unos años en que la prensa todavía sufría los límites de la censura. A pesar de ello, señala Groshman -citado por Antonio López Hidalgo- que es en los años sesenta cuando "un nuevo periodismo comienza a gestarse" (2012: 20) y que experimentará su apogeo durante la Transición. Así pues, con el análisis de estos artículos, podemos llegar a afirmar que

1 Desde sus inicios en la prensa murciana en los años cuarenta del siglo XX hasta la última columna que escribió para $A B C$, se hallan épocas diversas y el ejercicio de más géneros, aparte de la columna, que enriquecen la figura periodística de Campmany. Durante los años cincuenta y sesenta, combinándolo con otras tareas como la de corresponsal en Roma o su programa en Radio Nacional, Campmany escribió, principalmente en Juventud, El Españoly Arriba, artículos literarios, entrevistas, ensayos y comentarios, críticas de teatro, crónicas de viajes y de fútbol, reportajes narrativos y necrológicas. En 1978, ya en ABC, Campmany se dedicó expresamente a la columna de opinión hasta el día de su muerte el 13 de junio de 2005.

2 Aquella etapa de Campmany se estudia en dos tesis doctorales. La primera: Recursos de humor en el periodismo de opinión. Análisis de las columnas periodísticas. Escenas políticas (1987), de la profesora Fabiola Morales, leída en junio de 1989. La segunda: La retórica del texto argumentativo en la columna de opinión Escenas políticas de Jaime Campmany (1983), de Lourdes Román, defendida en 2016. También el profesor Juan Cantavella analiza el romance periodístico en las columnas de Campmany en su artículo La columna en verso: recuerdo y presencia de poetas y versificadores, publicado en 2011 en Doxa Comunicación. 
las 'Pajaritas de papel' representan un antecedente preclaro, no solo ya en el marco de la obra periodística de Campmany -como base e influencia en su segunda época de columnista en $A B C$ que señala Cantavella-, sino también y especialmente como un hito a destacar que precede a la irrupción y edad dorada del columnismo español de los años 70 y 80.

La importancia de los periodistas literarios de aquel tiempo, como el caso de Jaime Campmany y sus 'Pajaritas de papel', es capital, pues iban fraguando con sus artículos un nuevo modo de decir y una nueva época en la que la prensa llegaría a convertirse en el denominado 'Parlamento de papel’3, y donde la columna de opinión tendría un gran protagonismo en la sociedad, en la historia de la prensa española y en su tradición literaria.

En cuanto a la estructura del artículo, se ha querido establecer una diacronía que comienza con los antecedentes a la época de las 'Pajaritas', es decir, con la experiencia de Campmany en Roma como corresponsal, para seguidamente entrar de lleno en el período investigado, que abarca desde 1966 hasta la mitad del año 1970. A partir de ahí Campmany escribe sus ‘Pajaritas' de manera intermitente hasta junio de 1971, cuando da por finalizada esta etapa.

\section{Metodología}

El periodista Alfonso Ussía escribe en el prólogo del libro de Campmany Cartas batuecas que "la gran producción literaria de Campmany está en las hemerotecas, y eso supone un mal lujo”. De modo que esta investigación ha tenido mucho de extraer de los archivos aquello que no volvió a reproducirse después de su publicación. Diferenciamos tres fuentes para nuestro estudio:

- $\quad$ Fuentes primarias. Se trata de las 'Pajaritas'. Gran parte de esta documentación ha sido hallada en el Archivo Personal de Campmany en su domicilio de Madrid, así como en el Archivo Municipal de Madrid Conde-Duque. Algunas de estas 'Pajaritas' se encontraban también en la recopilación de artículos que hizo el propio Campmany en 1997 bajo el título Doy mi palabra. Mis 100 mejores artículos.

- $\quad$ Fuentes secundarias. Se trata del acopio de monográficos, artículos científicos, publicaciones periódicas o testimonios que nos ayudan a realizar un contexto adecuado y veraz del periodismo de los años sesenta en España.

- $\quad$ El archivo de la palabra. Se refiere a las entrevistas a familiares de Campmany: su esposa Conchita Bermejo, su hijo Emilio Campmany y su primo hermano Francisco Javier Díez de Revenga, realizadas entre 2014 y 2016. Estos tes-

3 Según Daniel Vela, es a finales de los años sesenta y a lo largo de la Transición cuando en España aparece un Nuevo Periodismo, émulo un poco tardío de la corriente del New Journalism. Los primeros indicios de una "escritura informativa de creación" estuvieron protagonizados por autores como "Francisco Umbral, Manuel Vicent, Jaime Campmany, Rosa Montero, Manuel Vázquez Montalbán. Se trata de un desvío con respecto al periodismo tradicional: se aceptan las técnicas literarias como válidas para el periodismo. Se busca apasionar al lector, conseguir la comunicación emotiva sin necesidad de que el mundo sea ficcional, sino mostrando la actualidad como contenido" (Vela, 2009: 697). 
timonios han resultado de vital importancia para trazar con precisión biográfica esta etapa del autor, además de aportar un punto de humanidad al texto.

La estructura de este artículo contiene un orden dividido en tres partes: primero, se sitúa biográficamente a Campmany, antes de su época de las 'Pajaritas' y el período en que se encuentra cuando las escribe; en segundo lugar, se contextualiza someramente el ambiente periodístico de la década de los años sesenta, el incipiente pero obstaculizado aperturismo que iba propiciando el género de la columna; y en tercer lugar, la aportación literaria de Campmany con sus 'Pajaritas de papel’ a ese periodismo de opinión en ciernes.

En este tercer apartado se elabora un análisis de las 'Pajaritas' y una clasificación de las mismas en una tipología, basada principalmente en el contenido. Lo que se pretende es realizar una teorización de estos textos según su temática, el lenguaje literario empleado, el valor de la sinceridad como defensa de la libertad de expresión, el propósito y la intención del autor, y el impacto que tuvieron en la sociedad y en el periodismo de aquel entonces.

\section{Situación del periodismo a finales de los años 60}

Después de una estancia de cuatro años en Roma como corresponsal para la Agencia Pyresa, Campmany regresa a España en enero de 1966 nombrado director de dicho medio. En Madrid compagina la dirección -hasta 1970- con la escritura de las 'Pajaritas de papel' en Arriba. La inserción de estas columnas en un diario de la Prensa del Movimiento se producía en un tiempo en el que el periodismo en España se iba transformando y experimentando, aun tímidamente y con impedimentos - "la prensa seguía siendo cercenada por la censura” (Vela, 2009: 623)-, cierto aire aperturista. Esto alentó en el ambiente periodístico la forja de un periodismo de opinión que alcanzará su cénit en los años de la Transición.

Como ya se ha dicho, los obstáculos frenaban este aliento de libertad, de modo que, como expresa Delibes en un artículo en 1968, "la libertad de los periodistas se ve cada día más mermada. O sea, que la libertad, en este caso, progresa para atrás como los cangrejos” (2010: 12). La Ley de Prensa de 1966, también conocida como 'Ley Fraga', seguía siendo una traba para el ejercicio pleno del periodismo libre. Y aunque se reconocía la libertad de expresión, "tales libertades no eran totales, sino que el Estado continuaba siendo vigía de la actividad periodística" (Vela, 2009: 623). Las condiciones del artículo segundo ponían el límite y truncaban las posibilidades del primero: "La libertad de expresión y el derecho a la difusión de informaciones, reconocidas en el artículo primero, no tendrán más limitaciones que las impuestas por las leyes. Son limitaciones: el respeto a la verdad y a la moral; el acatamiento a la Ley de Principios el Movimiento Nacional y demás Leyes Fundamentales (...)" .

4 Fragmento del artículo segundo de la 'Ley Fraga' extraído del texto de Pablo López Hurtado. Recuperado de: http://233grados.lainformacion.com/blog/2012/01/la-ley-fraga-luces-y-sombras.html [Consultado el 05/04/2017]. 
Esto significa que durante los años en que Campmany escribe sus 'Pajaritas' se siguieron tomando medidas “que hicieron ver que el Estado no se iba a desentender del control de la prensa, y que a pesar de la nueva ley de 1966 no se podían albergar esperanzas de un gran espíritu aperturista” (Vela, 2009: 624). Por esta razón, Campmany recordó su quehacer periodístico de aquel tiempo como un acto de valía: "en esos años escribí una columna diaria, marcada con la señal de identidad de una pajarita de papel, a la que le guardo un especial cariño, porque creo que logré decir muchas cosas que en aquel tiempo estaban prohibidas, gracias a usar un tono de humilde intimismo y hasta de reproche lírico" (1997: 21).

En el caso de las 'Pajaritas de papel' asistimos a un período en el que la impronta literaria de Campmany alcanza altas dotes de sublimidad, enriqueciendo estilísticamente al periodismo de aquellos años, especialmente al género del articulismo $^{5}$, y reivindicando con su anhelo de libertad una apertura que estaba en el horizonte. Mucha importancia e influencia tuvo en todo esto su anterior experiencia de corresponsal en Roma, pues resultó valiosísima para su concepción del nuevo periodismo que se iniciaría pronto en España. Dice Francisco Umbral que Campmany, "que había traído de Murcia muchas letras clásicas, era un ilustrado que se diera en Roma otro baño de clasicismo y nuevo nacimiento, o quizá Renacimiento" 6 .

\section{Resultados}

\subsection{Experiencia democrática en Roma y robustecimiento literario}

De ser cronista de fútbol a finales de la década de los cincuenta y primeros años de los sesenta, Jaime Campmany pasa a ser corresponsal en Roma, de 1962 a 1966. El periodista llegó a la capital romana en uno de "los momentos más interesantes del siglo" (Campmany, 1997: 19). Se celebraba el Concilio Vaticano II e Italia vivía un interesante momento político con el nacimiento del centro-siniestra, un entendimiento del socialismo con la democracia cristiana. El hecho de vivir durante un tiempo en una democracia resultó paradisíaco para Campmany, sobre todo por airearse al "salir de España y vivir cuatro años en Roma, en aquella época en que viajar era más difícil y que Italia era la dolce vita”?

5 Antes de la Transición democrática al columnista se le denominaba articulista. Hoy existe un distingo entre ambos géneros. En La columna. Periodismo y literatura en un género plural, López Hidalgo señala la distinción entre artículo y columna valiéndose de la tesis de Susana Gómez Reyna, quien establece las diferencias entre ambos géneros. "Para la autora, el articulista persigue establecer una tesis, defender o atacar una posición. Por el contrario, el columnista pretende dar a conocer sus opiniones personales en torno de un acontecimiento específico. (...) El artículo generalmente adopta la forma argumentativa, a veces la forma expositiva, y de manera más extraordinaria la narrativa o descriptiva. Mientras que en la columna son comunes la exposición, la descripción y la narración” (2012: 43-45).

6 Fragmento extraído del artículo de Francisco Umbral, publicado el 28 de febrero de 2001 en la edición impresa de El Cultural de El Mundo. Recuperado de: http://www.elcultural.com/revista/letras/Jaime-Campmany/2966 [Consultado el 05/04/2017].

Entrevista con Emilio Campmany en diciembre de 2015. 
En Italia experimenta Campmany lo gratificante que resulta la valorización de su oficio. Y es que cuando los nuevos vecinos le preguntaban a Conchita Bermejo, la esposa de Campmany, que a qué se dedicaba su marido y ella contestaba que era "giornalista», la gente se entusiasmaba ${ }^{8}$. En los años del franquismo, "si la prensa estaba conceptuada como una institución al servicio público, los periodistas pasaban a ser algo así como «funcionarios» de esa institución al servicio de la propaganda del régimen" (Pizarroso, 1992: 171). Esto, sumado a que la Escuela Oficial de Periodismo pertenecía a los organismos del régimen y la profesión periodística estaba aislada de la universidad, incrementaba la desvalorización de la profesión.

Por ello, la vuelta de Campmany a España en 1966, nombrado director de la Agencia para la que había sido corresponsal, produjo al principio un pequeño desencanto en él, pues su deseo no era el de retornar por el momento a su tierra, sino el de continuar la corresponsalía:

"Confieso que vine a Madrid de mala gana. Mi deseo hubiera sido irme a París de corresponsal durante cuatro años antes de regresar aquí. Se aproximaban los años de la transición española, y si esos años se presentaban interesantes, más interesante me parecía verle los entresijos a las democracias antes de que llegaran a España. De hecho, mi experiencia italiana, un país cuyo momento histórico era en cierto modo muy semejante al español, fue para mí valiosísima. Italia había salido de un régimen dictatorial para entrar en una democracia plena y formal, y eso es lo que iba a suceder en España." (Campmany, 1997: 20)

En cuanto al estilo de aquellas crónicas de agencia, Campmany comentó en una entrevista que se trataba de "crónicas urgentes, dictadas por la actualidad romana. Sólo de vez en cuando practicaba la pirueta, cuidaba más la forma que el fondo. Al regresar a España potencialmente me hallaba robustecido" (Línea, 29/01/1967). Tanto es así que al partir de Roma hacia España Campmany ofrece a los lectores una última crónica sentimental del corresponsal que se despide nostálgicamente de la ciudad donde ha vivido cuatro años inolvidables. Con el título de Adiós, mamá Roma, el artículo se publicó el 2 de enero de 1966, y creemos que puede ser el germen de la expresión futura de sus 'Pajaritas':

"Te he dado cuatro años de mi vida, mamá Roma, y ahora sé que te hubiese dado la vida entera, la luz toda de mis ojos, mi canto todo, mi lengua sólo para ti, mi corazón que ya me lo has ganado sin remedio. Cuatro años contigo, mamá Roma, y ahora que me parto de ti pasa por delante de mis ojos empañados el desfile de las ternuras, de los asombros, de los grandes regalos que me has hecho, de los días que he vivido sentado en tus rodillas, como dicen que pasan las escenas de la vida, en una película rápida y límpida, por el recuerdo urgente y excitado de los que van a morir." (1997: 322-324).

8 Entrevista con Conchita Bermejo en mayo de 2014. 


\subsection{Anatomía de las 'Pajaritas de papel'}

El 9 de junio de 1966 Jaime Campmany inaugura en Arriba su primera 'Pajarita', titulada Pajaritas de papel. En este primer artículo el periodista, además de dedicársela a Miguel de Unamuno "porque el rector de Salamanca ha sido el único cocotólogo del universo, que yo sepa, y el que nos ha dicho todo lo que se sabe acerca de las pajaritas de papel”, explica en qué va a consistir "la nidada de pajaritas":

“... esta de hoy es la primera de una nidada de pajaritas de papel que han encontrado su pajarera y su cobijo en esta ventana de $A R R I B A$, a la que ustedes podrán asomarse, si quieren, un ratito todas las mañanas. (...) la pajarita, la cocotte en francés, que de ahí viene cocotología, es un ser casi perfecto y armonioso, y por ello la tomo yo como símbolo, cifra y emblema de mis renglones diarios." (Arriba, 09/06/1966).

En este primer artículo Campmany habla del concepto geométrico de las pajaritas de papel y destaca tres puntos a partir de los que se articularán sus 'Pajaritas'. "En los trabajos y los días de mi vida de periodista no busco otra cosa que ir plegando pajaritas que se mantengan en pie sobre esos tres puntos (...), uno, el de la viveza; otro, el de la ternura, y el tercero, el de la ironía" (1967a: 3). Campmany teje periodismo y literatura mediante estos tres pilares. Trabaja un presente con herramientas de la ficción que acaban por convertir a artículos, aparentemente con una vida de un día, en imperecederos. Así pues, estas 'Pajaritas' permanecen en el tiempo tras eslabonar actualidad, humanidad y forma literaria en sus tres puntos de apoyo:

"Porque mal se puede escribir todos los días en el periódico, que es mercancía tan delicada como las rosas que se amustian a la tarde cuando nacieron por la mañana, algo que no tenga la viveza de lo actual; porque creo que los españoles, aquí y ahora, estamos necesitados y menesterosos de poner ternura en nuestras miradas y en nuestras palabras, ya que tan habituados estamos a mirarnos todos los unos a los otros con hosquedad, envidia, recelo, y a veces inquina, y algunas otras veces hasta odio; y porque la ironía es cosa que, sin hacer demasiado daño, sirve en ocasiones para decirle las verdades del barquero al lucero del alba, y produce más sonrisas que escándalos (Campmany, 1967a: 3-4)”9.

9 Estas palabras las pronunció Campmany en una conferencia en Murcia el 31 de octubre de 1967. El diario Línea la publicó íntegra en su suplemento Murcia Documento el 5 de noviembre de ese año. 
Cuadro 1. Primera ‘Pajarita’ de Jaime Campmany en el diario Arriba. 09/06/1966

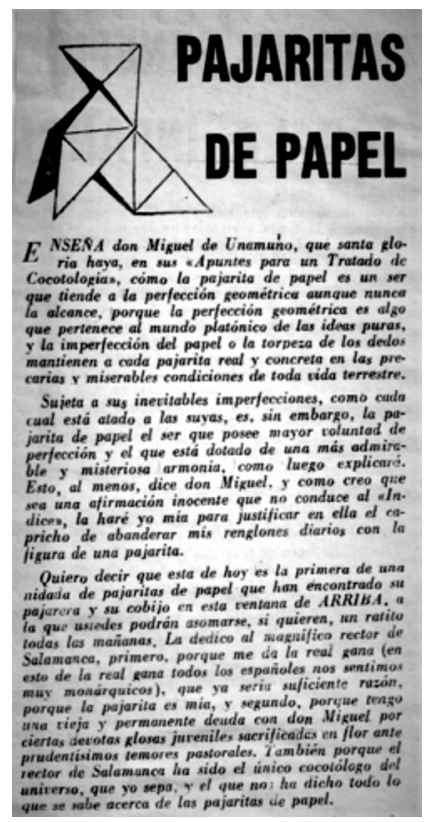

Fuente: Archivo Personal de Jaime Campmany

1.- Viveza. Entendemos esta palabra como alegoría de actualidad. En los ejemplos veremos cómo ternura, ironía y prosa literaria devienen de un hecho actual: ya sea el fallecimiento de algún personaje público, una efeméride, o incluso la entrada del otoño o del verano. En suma, la viveza es el bastión periodístico del que brota la 'Pajarita’:

“Gerardo Diego, profesor y poeta, profesor entre los poetas y poeta entre los profesores, ha pronunciado su última lección en el Instituto «Beatriz Galindo» (...) Gerardo se calza hoy las zapatillas de la jubilación.” (1997: 49).

2.- Ternura. El detalle tierno y lírico son características muy enraizadas en la prosa periodística de Campmany. En sus 'Pajaritas' hallamos momentos en los que el autor se detiene y regodea en observaciones entrañables, humanas, que nos llevan incluso a establecer posibles influencias del cine español de posguerra, como el de Berlanga, o el neorrealismo italiano.

"Eras bueno, Manuel ${ }^{10}$. Yo sé que hoy, primer día después de tu muerte, estarás buscando al Niño mientras maduran las uvas en los viñedos celestes, y con tu guasa inocente de Baco socarrón y sentimental le harás esa pregunta del más desconcertante villancico castellano:

10 Se trata del poeta Manuel Fernández Sanz, conocido con el sobrenombre de Manolo el Pollero, fallecido en 1966. Es de su autoría el villancico del Niño Jesús que reproduce Campmany en su necrológica. 


\section{Cuando con los otros niños}

de niño jugabas tú,

¿sabías o no sabías

que eras el Niño Jesús? (1997: 45).

3.- Ironía. Sin duda, fue una de las técnicas sutiles, además del tono intimista, que le permitió a Campmany expresar ciertas cosas que en aquel tiempo todavía estaban prohibidas. Esta ironía, además, se convirtió en el preámbulo de su vena humorística y satírica que llevaría a plenitud en su segunda etapa como columnista en $A B C$.

“¡Pobre bellísima, admirada, aplaudida, celebrada y deseada Ava Gadner! ¡Pobre y envidiada mujer! ¡Pobre y desdichada Ava Gadner, envejecida dentro de la jaula de oro de la fama (...) vapuleada sin tregua por la espantosa paliza de la gloria!” (1997: 47).

\subsubsection{El lenguaje sincero de la 'Pajarita' como defensa de la libertad de expresión}

El valor de la sinceridad acompaña a Campmany desde sus comienzos. Cuando irrumpe en el panorama literario de la Murcia de la posguerra con su poemario Alerce (1943), el propio Campmany, a la edad de 20 años, declara en una entrevista para La Verdad de Murcia que su libro goza de "un sentido de sinceridad, que tan raro es encontrar en la poesía actual" (20/12/1945). Sus versos habían cautivado a un público amplio gracias a esa "sensibilidad lírica, conseguida con acentos sinceros” (Línea, 01/05/1947). Díez de Revenga, refiriéndose a los escritores jóvenes de aquel momento entre los que se encontraba Jaime Campmany como uno de los poetas más prometedores, dice que "era un grupo de autores integrado en la modernidad de aquellos años por la vía de la sinceridad" (2005: 9) ${ }^{11}$.

Igual que el estilo poético fue injertándose en la prosa periodística de Campmany, apreciamos también cómo la sinceridad poética que caracterizó a sus primeros escritos en verso favorece la querencia hacia la libertad de expresión, a pesar de la época de censura que le tocó vivir. Escribe Campmany: “Jamás he escrito una letra bajo soborno, por miedo o por adulación. Mis palabras serán yerros o miserias, pero todas son mías, muy mías y nadie me las dictó nunca, y si algunos intentaron dictármelas, yo no las copié. He escrito siempre lo que pensaba desde la sinceridad" (1997: 14).

La RAE expone el significado del término sinceridad con adjetivos - "sencillez, veracidad, libre de fingimiento" 12 - que definen también la esencia del Periodismo: lenguaje claro y sencillo, defensa de la verdad, libertad de expresión. Este modo

11 Para más información sobre esta época de Campmany en Murcia puede leerse el artículo de Fernández, A. (2016): "Murcia: Tierra y corazón de Jaime Campmany", Mvrgetana, no 135, pp. 171-193. URL: http://www.regmurcia.com/docs/murgetana/N135/N135-07.pdf [Consultado el 06/04/2017].

12 Definición de la Real Academia Española consultada en el Diccionario en línea. Recuperado de: http://dle.rae.es/?id=XwnKRc7 [Consultado el 05/04/2017]. 
de expresarse sin fingimiento está imbricado en el periodismo de Campmany, quien, en una 'Pajarita' titulada El perfil amable y publicada el 24 de agosto de 1967, recrea una conversación con un político de aquellos años sesenta, que le insta a cambiar el tono crítico de sus 'Pajaritas' con el fin de "ayudar a la gente a que olvide los problemas, las faltas, las injusticias, las fealdades. Hay que retintarles el perfil amable de las cosas (...) Si yo tuviese algún ascendiente o autoridad sobre ti te prohibiría escribir esos artículos críticos que parecen dictados por un eterno descontento". Pero Campmany le replica al político que él siempre escribirá desde su yo sincero:

Campmany: “-Yo también escribo del perfil amable de las cosas, del perfil amable de los acontecimientos, del perfil amable de los hombres".

Político: “-Pues así es como deberías escribir siempre”.

Campmany: “-Entonces no sería objetivo, deformaría la realidad que tengo alrededor de mí. Y sobre todo, no sería sincero. El único valor que puede tener lo que yo escriba es el de la sinceridad, el de contar lo mejor que pueda aquello que miro, aquello que considero, aquello que pienso. Tú pretendes que yo haga un periodismo «rosa» y la vida no es toda de color de rosa, la historia de la vida no es una novela «rosa»" (Arriba, 24/08/1967).

Poco antes de cumplirse un año de la publicación de la primera 'Pajarita', Campmany escribe Razón de amor, publicada el 27 de mayo de 1967, donde afirma que son muchas las palabras que hay que decir en este país, "donde mi 'Pajarita' nació y donde mi 'Pajarita' vive y al que mi 'Pajarita' ama”; un país que necesita "una voz generosa y muchos reproches que esperan una voz sincera. ¡Tenemos tantas cosas que decirnos los españoles por debajo de las solemnidades huecas y de los altos debates!”. Hay un reclamo de humanidad. En su última 'Pajarita', publicada el 1 de junio de 1971, Campmany escribe una frase reveladora: "A la pajarita y a mí nos gustaría poder decir al final de nuestras vidas casi paralelas aquello que se dejó dicho Tácito: Nada de lo humano me es ajeno". Y es que la materia humana alimenta sus artículos. Así lo expresa en Alpiste para la pajarita:

"Yo os cuento todas las cosas que me suceden, las buenas y las malas, y os cuento las cosas que os suceden a vosotros mismos, también las buenas y las malas. Y así nos vamos conociendo todos. Y sabiendo los problemas de unos y otros. Y así mi «Pajarita» tiene un poco de alpiste para llevarlo a su pequeño buche de papel y seguir viviendo. Viviendo y cantando. Cantando el dolor y la esperanza" (Arriba, 19/10/1967).

\subsubsection{El lenguaje poético de la 'Pajarita' para un periodismo literario claro y sencillo}

Para lograr la sinceridad de la que venimos hablando se necesita hablar en plata, abandonar "los eufemismos, las alusiones secretas, los rodeos tortuosos, las claves cifradas, las frases abstractas, intrincadas y vagorosas". Esto lo dice Campmany en otra 'Pajarita' titulada Hablar, en la que aboga por un lenguaje periodístico despojado de los recursos apañados y abstrusos que servían para evitar la censura pero que dificultaban la comprensión: 


\begin{abstract}
“Alguna vez mi 'pajarita' ha pedido que se hable en plata. (...) Que los que escribimos en los periódicos nos vayamos despojando de los varios trucos y recursos de los que en estos años pasados nos socorríamos para meter un gol a los censores o para hacer una sugestión a un Ministro o aguijonear a la Administración sin que se enteraran otros lectores que los pocos que estaban en el secreto. Era aquella una manera de ejercer una crítica prácticamente clandestina y privada de toda peligrosidad, y también de convertir la crítica en un ejercicio inoperante y estéril" (Arriba, 04/10/1967).
\end{abstract}

Sostiene Campmany en Hablar que lo mejor para alcanzar la sinceridad y la claridad periodísticas es "volver al estilo poético, en el sentido machadiano de la palabra". Campmany rememora aquella escena de Juan de Mairena de Machado en la que el maestro escribe en el encerado: «Los eventos consuetudinarios que acontecen en la rúa» y le pide a su alumno Martínez que redacte esa misma frase pero en lenguaje poético. El alumno escribió: «Lo que pasa en la calle». Y al maestro Mairena no le pareció mal. "Lo mejor es volver al estilo poético (...) Me parece que todos tenemos que aprender algo del alumno Martínez", afirma Campmany, quien cree en este lenguaje claro y sencillo como ejercicio de humildad para el buen hacer y el buen decir del periodismo.
"Creo yo que, sobre la virtud de la claridad y la sencillez, los periodistas de esta nueva etapa debemos adornar- nos de la virtud de la humildad, y acostumbrarnos a conformar nuestras opiniones propias con las opiniones de las gentes que nos rodean, de las gentes que andan por la calle, de las que nos leen y de las que no nos leen, de las que creen que todo ese diálogo público que han abierto los periódicos es algo convencional, como si los 'parlamentos' estuviesen escritos y repartidos de antemano. (...) Creo yo que somos nosotros los que en este mo- mento podemos recoger esa pública opinión y darle nuestra voz, poniéndola previamente en “lenguaje poético” (Arriba, 04/10/1967).

Cuando en 1947 Campmany publicaba su segundo poemario Lo fugitivo permanece en la revista murciana Azarbe, José Ballester, escritor y periodista murciano, director de La Verdad en esos años, destacó que el propósito del joven poeta "es el de captar y fijar momentos" (La Verdad,19/07/1947). Y, para que veamos el propósito similar en periodismo, Campmany, medio siglo después, apunta palabras similares a las de Ballester en una entrevista en Radio Nacional cuando el entrevistador le pregunta qué aconsejaría a los estudiantes de periodismo y Campmany destaca la importancia de la lectura para poder "contar lo que contemplamos en la vida; tenemos que definir las cosas: los muebles, las situaciones, los paisajes, los sentimientos de la gente, y todo esto no se puede contar si no se conocen las palabras" (RNE, 07/04/1997). He ahí el valor añadido del periodismo literario. Captar y fijar la actualidad con el apremio del periodismo y con la recreación sosegada de la expresión literaria a la vez.

Ya dijo Kramer que el periodismo literario es ese periodismo "en el que las artes estilísticas y de construcción narrativa asociadas desde siempre con la literatura de ficción ayudan a atrapar la fugacidad de los acontecimientos, que es la esencia del periodismo" (López y Gómez, 2010: 119). Y además de procurar un lenguaje cuidado y que embellezca la información, 
la ayuda de las herramientas de la literatura amenizan y agilizan la lectura y no la densifican ni la barroquizan. La literatura con fines meramente ornamentales sí supone un fracaso, además de que, como dijo Delibes, "desapareció el día que el arquitecto Perret reconoció «que el adorno oculta siempre un error de construcción»” (2010: 36).

\subsection{Clasificación y ejemplos de 'Pajaritas'}

Podríamos escoger muchos modelos de tipología de columna periodística con el fin de catalogar las 'Pajaritas' de Campmany, asumiendo además, como señala Antonio López Hidalgo, que la columna es “un género inclasificable” (2012: 165). Sin embargo, "las tipologías de género pueden ser infinitas", además de que se podrían diseñar distintas clasificaciones "atendiendo a su temática, su funcionalidad, su estilo o su estructura" (López, 2012: 165).

Las ‘Pajaritas de papel' pertenecen a esas dos modalidades más narrativas de la columna propuestas por Irene Andrés-Suárez: la columna-microrrelato y la columna-poema en prosa. La primera se refiere a aquel texto periodístico que se articula según las características de los microcuentos, compartiendo características como "la brevedad, concisión, intensidad, condensación, máxima economía de medios, eliminación de todo lo accesorio, omisión y expresividad, calidad estética" (López, 2012: 164). En cuanto a la segunda categoría, las columnas en prosa "plasman por lo general momentos de gran intensidad emocional y constituyen verdaderas efusiones líricas transmitidas en primera persona gramatical” (2012: 165).

Para este trabajo, clasificaremos las 'Pajaritas' según la temática, pues estos artículos oscilan, en suma, entre lo reivindicativo, lo nostálgico y la recreación de sucesos; siempre con la presencia del yo del articulista y la clara exquisitez de un periodismo literario de calidad.

\subsubsection{Pajaritas audaces}

En la 'Pajarita' del 21 de junio de 1966 Campmany recordó un poema de Pablo Neruda de aire estival, propicio para la entrada del verano. Dice Daniel Vela que, a pesar de que en aquellos años de finales de los sesenta hay quienes tratan de impedir que se citen a determinados autores, Campmany quiere reivindicar su derecho a hablar sobre un poeta de su predilección como es Neruda (2009: 672). Así comienza el artículo:

"Entra hoy el verano. Y yo escribo: «Verano violín rojo». Digo que hoy entra el verano para tener el pretexto de escribir: «Verano violín rojo». Cito a Pablo Neruda, cuyos versos son los versos más altos de la viva y ancha lengua azul de Castilla. Cito a Pablo Neruda. Su verdadero nombre: Neftalí Reyes. Chileno y comunista.

Quiero citar adrede a Pablo Neruda, imprimir su nombre preciosamente en estas páginas, poner su nombre aquí, encima del mío. (...) Yo sé que hay algunos que dicen: «no citarlos, no mentarlos, no pronunciar sus nombres. No repetir sus versos»" (Campmany, 1997: 125). 
Campmany, que en una conferencia en 1967 expresó que su 'Pajarita' "es amiga de los poetas, y de ellos habla y de ellos se socorre y alivia" (1967a: 4), reivindica su derecho a citar a estos autores porque ama un país en el que "no estén desterradas las palabras claras y los versos bellos" (1997: 1297). Exclama una apertura que estaba en el horizonte. De modo que escribir estos párrafos que escribe Campmany, asumiendo los riesgos de la rigidez del régimen, era un hecho extraordinario todavía en un tiempo de ordinariez.

“Amo una España nueva donde los poetas no tengan que volver a escribir a sangre y fuego, donde el viento del pueblo no tenga que volver a soplar huracanado (...) donde al españolito que nace no le hiele el corazón una u otra mitad de su Patria, donde triunfen los veinte poemas de amor y no la canción desesperada, donde se lea el canto a Stalingrado con la misma serenidad que la Araucana. Amo una España donde se pueda decir con Neruda que el verano es violín rojo (...) Amo una España de la cual no estén desterradas las palabras claras y los versos bellos, donde puedan hablar, sin morir, Alberti el empecinado y Pemán el impaciente... ¿̇Será eso posible?" (Campmany, 1997: 125-127).

\subsubsection{Pajaritas de la nostalgia}

Una de las características principales de la columna es la presencia del yo. Bajo un halo intimista y de confidencia, Campmany deja también en sus artículos “una impronta de sí mismo”, en expresión de López Pan (Ruiz de la Cierva, 2012: 1745); de modo que permite que muchos lectores se acerquen a su columna diaria por afinidad de pensamiento. "De ahí nace una característica esencial: la fidelidad al columnista y la atmósfera de intimidad que existe entre columnista y lector" (2012: 1745).

Los fragmentos del artículo propuesto tienen mucho de esa estrecha unión entre el yo autor y el yo lector en el acontecimiento nostálgico del regreso a la casa donde se nació. Recordemos que el regreso es uno de los grandes temas de la literatura universal, como por ejemplo La Odisea de Homero con el relato del retorno de Ulises a Ítaca. Con el título La herida del tiempo, publicado el 15 de septiembre de 1967, Campmany narra también su particular regreso a Ítaca. El sentimiento y las remembranzas rodean a su inspiración y se lanza a construir un artículo en el que la escritura se siente más que nunca sinónima del llanto.

"Escribo desde la casa en que nací. Nunca como en estas horas en que vuelvo a la provincia, me duele tanto la herida del tiempo. Miro hacia los rincones poblados de sombras y se me sobresalta el corazón, porque los recuerdos se me convierten en presencias casi vivas, que luego se desvanecen con un indefinible dolor de haberlas perdido otra vez. La mano se me va, sin mirar, hacia algún viejo objeto querido, y, también sin querer, se me hace cóncava para la caricia. Se me pierde entonces la mirada y el tiempo regresa sobre los pasos que yo creía irreversibles. Vuelvo a revivir las escenas tiernas de mi niñez, los años combatidos de mi adolescencia, las ilusiones de mi primera juventud". 
Campmany observa los objetos de su vieja casa que le descubren toda una memoria que él creía olvidada, en una mágica y literaria fusión entre el presente ajado y el pasado feliz.

"Caigo en una especie de rapto. Quizá sueño, quizá recuerdo, quizá muero. Las cosas de mi vieja casa pierden su sentido de utilidad. Miro el reloj, el reloj no es algo que señale la hora, sino una caja mágica de donde salen viejas horas, memorias agolpadas, palabras y ademanes que yo creía archivados para siempre en el olvido. Miro un libro, y no veo sus páginas repletas de letras como sucesivos renglones de hormigas, sino algo así como un fluido invisible que rodea su volumen, que se despega del olor de la encuadernación. Veo unos dedos blancos y finos que tuvieron aquel servilletero de plata abollado, que pusieron rosas o jazmines en aquel búcaro desportillado, que ordenaron la ropa blanca en el cajón crujiente de aquella vieja cómoda, que trenzaron la maraña amarillenta de aquel tapete complicado.

Escribo desde la casa en que nací. Caen desde la torre las campanadas de los últimos conjuros. Se escucha la voz de la vecina en el balcón, al través de la calle estrecha y sombreada. En los tiestos hay jazmines que deben ser bisnietos de aquellos que yo veía regar. Hay una porcelana rota que yo pegué una noche, ya lejana, con Syndetikón, con clandestinidad casi criminal. Hay un viejo retrato que yo miro, que yo miro, que yo miro, que yo miro sin poder apartar los ojos, y que sigo mirando aunque los ojos me escuecen, y que sigo mirando aunque los ojos me lloran".

En este punto emotivo del artículo, Campmany interpela directamente al lector y le pregunta si le ha ocurrido lo mismo que le está aconteciendo en ese instante al articulista: “¿Se os ha muerto alguna vez una vieja casa? ¿Se os ha muerto alguna vez la casa donde nacisteis? ¿Se os ha muerto alguna vez la casa donde murieron todos los seres que amabais?”. Este texto de gran calidad literaria, entre la columna-microrrelato y la columna-poema en prosa, trasluce un sincero y emocionante sentimiento de humanidad ejemplificado en el momento en que Campmany encuentra algunas cartas de sus padres:

“Y luego los papeles. Hay papeles amarillentos, con letras de tinta casi desvaída por los años. Una tinta violeta pálido, como de lirio marchito. Hay cartas que empiezan así: «Queridísimos padres». Y otras: «Queridísima mamá». Y otras que terminan: «Sé bueno, hijo mío. Sé siempre bueno y temeroso de Dios, y que la Virgen te acompañe y te traiga pronto entre nosotros». ¡Cómo duele en estas cartas la herida del tiempo!”.

En el último párrafo Campmany despierta de los recuerdos, aunque todavía sigue en una actitud introspectiva, y se da cuenta de que se ha hecho de noche; se pregunta cuánto tiempo lleva así, quieto y en silencio:

"Está cayendo la tarde. i Cuántos minutos he permanecido así, quieto, silencioso, como en un rapto, sin poner en la cuartilla una nueva palabra? No sé. La casa se está quedando oscura. Parece ahora que las sombras se muevan. Sucede algo extraño: se oyen voces que no rompen el silencio. Pasan las voces al través del silencio como los rayos de luz por el cristal. ¡Dios mío! ¿̨eré un alucinado? Se va dulcemente la tarde por los caminos dulces 
de septiembre. Han enmudecido las campanas. Estoy sentado, con las manos colgantes, como enfermo, no sé si de nostalgia o de la pálida dolencia del desaliento. Me duele, como nunca, la herida del tiempo. Esta herida del tiempo que nunca terminará de cicatrizar. No sabría decirlo con certeza, pero tal vez esté llorando. O escribiendo. A veces es lo mismo" (1997: 328-330).

\subsubsection{Pajaritas de sucesos}

Otras 'Pajaritas' caminarán en la línea del comentario literario acerca de acontecimientos externos a la introspección del autor. Las dos que aquí destacamos tratan, la una, sobre el desbordamiento del río Arno en Florencia y, la otra, sobre el derrumbamiento del techo de un aula donde se estaba impartiendo una clase, consecuencia del estado pobre de algunas escuelas españolas a finales de los años sesenta.

El 13 de enero de 1967 la ‘Pajarita’ de Campmany llevaba por título Llanto. Habían transcurrido dos meses desde la tragedia en Florencia y Campmany, que tan unido a Italia estaba, y que diría en una entrevista que Florencia es su ciudad favorita, "su ciudad soñada" (La Verdad,12/11/1995), justifica de manera muy poética el porqué de su demora en escribir sobre este suceso: "No encuentro otra disculpa para la tardanza de mi llanto que la de pensar que así no acreceré las aguas con mis lágrimas”:

"Florencia dormía. Florencia dormía como una princesa. Florencia, amigos, es la ciudad más bella de los mundos. Florencia, lugar de flores. Florencia, joya de piedra. Florencia, museo del Occidente. Sin Florencia, Europa apenas sería una leve huella sin importancia en la Historia del Arte, que es como decir en la historia del hombre. Florencia dormía cuando las aguas rompieron lo paseos que se alargan en las márgenes del río, e invadieron las calles y las plazas, y asaltaron las bibliotecas, los talleres de los orífices y de los artesanos, los sótanos de los anticuarios".

Campmany describe con metáforas y símiles cómo muchos monumentos florentinos y clásicas obras de arte sufrieron de improviso el trágico suceso:

"El puente de las Gracias se ve como la cubierta de un barco que se va a pique. El ábside de la Santa Croce se refleja en el espejo oscuro de las aguas fangosas. El mármol de las estatuas tiene el agua por la rodilla. Los florentinos luchan contra la corriente; se asen desesperadamente a una tabla que pasa, que quizá guarde el secreto del arte de siglos asombrosos (...) Ha irrumpido el Arno en el centro histórico de la ciudad. El "borgo Pinti” es sólo un pantano fangoso. El Cristo de Cimabue. (...) ¡Venid, socorrednos! Paolo Ucello está bajo las aguas en el claustro verde de Santa María Novella. También las huellas divinas de Botticcelli en la iglesia de Ognisanti. Naufragan los frescos de Lorenzetti, de Simone Martini, de Domenico Veneziano. Las aguas enloquecidas improvisan una música patética sobre los instrumentos del Museo Bardini”. 
En ese estado de impotencia en que se suelen expresar las grandes intenciones, Campmany dice poéticamente que si tuviera un pincel mojado en sus lágrimas y en su sangre podría recomponer algunas de las piezas perdidas:

"Yo tenía la obligación de llorar sobre Florencia. Yo tenía la obligación de dar este grito, casi ahogado, sobre la tragedia de Florencia y poner sobre el recuerdo imborrable que habita en mis pupilas enamoradas este lamento tardío, esta palabra plañidera y desolada. Lloro sobre Florencia. Y si mis manos pudiesen manejar un pincel de privilegio, lo mojaría en mis lágrimas y en mi sangre para recomponer, milímetro a milímetro, el Cristo de Cimabue. (...) Sólo tengo lágrimas, y las vierto hoy sobre Florencia, la ciudad más bella de los mundos" (Arriba, 13/01/1967).

El 10 de julio de 1966, en otra 'Pajarita', que se tituló Escuela para pobres, Campmany relata los minutos previos al derrumbamiento del techo en una escuela de Madrid y del que se sirve el autor para reprochar la paupérrima situación de algunas escuelas españolas de aquellos años. Este artículo, formalmente, resulta una clara columna-microrrelato, pues goza de una estructura narrativa tal, que la concisión estilística, la descripción de los personajes, la tensión creciente y el clímax del final sintonizan con la esencia de un relato de ficción que, por desgracia, no lo es.

"El maestro dijo de nuevo ¡silencio! Cuando el maestro decía ¡silencio! con voz tajante e imperativa parecía detenerse la vida en el aula durante unos instantes. Igual que cuando se para la máquina de cine. Los niños se quedaron quietos, algunos con la boca abierta todavía en la sílaba cortada, moviendo sólo los ojos. El maestro dejaba caer al suelo, espectacularmente, un libro, un periódico doblado, un lápiz, una moneda. Y seguía explicando la ley de la gravedad".

Estas primeras líneas sobre las ideas de la gravedad, de “dejar caer al suelo, espectacularmente, un libro", serán premonitorias del trágico suceso del final. En los momentos anteriores al derrumbamiento, Campmany describe la pobreza del aula y las grietas en el tejado a punto de desgajarse:

"Algunas miradas distraídas trepaban por las paredes desconchadas, comidas por la lepra del tiempo y de la humedad. Algunas miradas distraídas se detenían en el mapa de los montes (...) Las miradas distraídas escalaban las paredes y luego se prendían en el techo y seguían el dibujo de las grietas, que formaba curvas y tomaba rumbos caprichosos como el trazado de las carreteras en un plano.

A uno de los pupitres le faltaba medio asiento. La tabla cortada se clavaba en ese sitio donde termina el pantalón corto y producía una señal roja como una cicatriz. Cuando los niños entraban en clase corrían hacia los pupitres mejores, y el que andaba menos listo, que siempre era el mismo, tenía que sentarse en el pupitre roto. Los niños conocían cada pupitre mejor que el libro, ya mugriento y manoseado. Sabían dónde estaban los clavos a medio salir, dónde las astillas medio levantadas, dónde los agujeros hechos a navaja..." 
Es difícil ser maestro en una escuela pobre. Se pone uno a dictar y hay niños que dicen que no tienen cuaderno porque su madre no lo puede comprar hasta el sábado. Coge uno el puntero para señalar los montes de España en el mapa «orográfico», y el Mulhacén está descascarillado, y los picos de Urbión, y los montes de Toledo. Hay niños que bostezan continuamente, no se sabe bien por qué. Hay niños que tosen durante todo el invierno. Hay niños que desaparecen de la escuela durante meses y luego vuelven sin recordar la lista de los Reyes godos, ni la tabla de multiplicar, ni la conjugación del verbo ser, ni los cabos de España”.

Llega el momento final. Una oquedad se abre en el techo y la tragedia está servida. El suceso perjudica más al maestro que a los niños, quienes acuden a socorrerlo de inmediato:

"El maestro decía que todo cuerpo tiende a caer a la tierra si no encuentra una fuerza mayor que lo mantenga en el aire. (...) Las grietas del techo eran cada vez más complicadas. Algunas miradas distraídas seguían el dibujo como quien resuelve un laberinto. Había grietas gruesas como ríos grandes y grietas finas como afluentes y subafluentes. Había una grieta gruesa, gruesa, como el Amazonas.

El maestro dijo ¡silencio! y siguió explicando. De pronto, se abrió el techo. Algunos niños gritaron de miedo. Los cascotes cayeron sobre el maestro, y el maestro cayó a tierra. Los niños bullían entre la polvareda. Los niños se acercaron al maestro herido. Le limpiaron la cara con los pañuelos sucios. El maestro, herido, seguía diciendo: «La ley de la gravedad...»".

Una vez cerrado el relato, Campmany anota con ironía, como si de un epílogo se tratara, los datos exactos del suceso: la fecha, el nombre del maestro, el barrio de Madrid donde se encuentra la escuela, y que convierten a los hechos de apariencia ficticia en una triste historia real: "No sé cómo se llama el maestro. Quizá Pedro Lorenzo Utrilla. No sé cómo se llaman los niños. Pedro, Juan, Francisco, etc. No sé cómo se llama el barrio. Tal vez se llame el barrio de Usera. No sé cómo se llama la ciudad. Seguramente Madrid. No eran los tiempos de Maricastaña. Tal vez fue en 1966” (1997: 128-130).

\subsection{Pajaritas de un tirón: literatura urgente, periodismo sosegado}

Afirman Santamaría y Casals que el artículo literario es “literatura urgente y es periodismo sosegado” (Gutiérrez, 2009: 41). Al intercambiarse los adjetivos apreciamos que hay una alteración del ritmo de ambas disciplinas, una cesión de sus características principales al servicio de una nueva rama de estudio humanístico: el periodismo literario. Y esto es lo que hacía Campmany. Se ponía delante de la máquina de escribir y le brotaban torrencialmente las palabras, caudalosas, hasta llegar a hilar de un tirón un texto que, habiéndose escrito con celeridad periodística, resultaba luego un remanso muy literario, de lectura sosegada. En 2004 habló acerca de esto en El Faro de Murcia en la que fue su última entrevista:

"A veces, sin saber de qué voy a hablar, me siento, medito cinco o seis segundos y pongo un título. Considero que poniendo un título ya tengo más de la mitad del artículo escrito. A partir de ahí, van naciendo ideas, saliendo 
cosas, asociando conceptos... y creo que esta facilidad se la debo al enorme caudal de lecturas que, desde joven han pasado por mis manos (...) Por eso ahora me resulta fácil escribir un artículo cada día, y a veces, incluso, dos o tres" (El Faro, 13/10/2004).

En relación a esta asociación de ideas que van dando forma al artículo, César González-Ruano dijo: "Las palabras tienen una magia especial, tiran las unas de las otras, son 'algos' que de manera fatal formarán un 'todo'” (Perlado, 2007: 20). Ruano hablaba de esa inspiración diaria para escribir de un tema distinto cada día. Y en el caso de Campmany sucedía igual. Muchos eran los que se preguntaban con verdadera curiosidad cómo podía encontrar siempre algo de lo que hablar todos los días en su 'Pajarita', y otros muchos auguraban que alguna vez esa fuente de inspiración se agotaría. Campmany les contesta con una 'Pajarita' publicada el 11 de agosto de 1966, titulada Cada día:

“Mirad, amigos. La vida está llena de temas para mis «pajaritas». Abro los párpados, echo la mirada en derredor y los ojos se me llenan de temas. (...) «Amor y poesía, cada día», era el lema de Juan Ramón. ¡Dios mío, y cuántas cosas para amar y cuántas cosas por decir se deja uno cada día! ¡Y cómo resbala nuestra mirada por encima de cosas y de seres sin detenerse a conocerlos un poco, a amarlos un rato! (...) ¡Y cómo pasamos, indiferentes, por encima de la lección eterna y azul del mar, de la humildad dorada y plural de la arena, de la constancia luminosa del sol nuestro de cada día, de los sueños, de los suspiros, de las esperanzas y de las lágrimas de estas gentes que nos rodean, de esas gentes que levantan nuestras casas, que amasan nuestro pan, que riegan las flores donde se recrean nuestras pupilas!" (Campmany, 1997: 325-326).

La catarata de palabras irrumpía sin cesar sobre la máquina de escribir. Francisco Javier Díez de Revenga, primo hermano de Jaime Campmany, tiene el recuerdo plástico de aquel sonido de las teclas cuando Campmany veraneaba en Campoamor con su familia en la década de los sesenta.

"Estábamos ahí todos hablando hasta que llegaba un momento en que Jaime tenía que mandar la 'Pajarita' a Madrid, y llegaba Conchita y le decía: «Jaime, la ‘Pajarita’, y él: «Sí, sí, ahora después la escribo, que estoy hablando con mis tíos y mis primos». Y entonces, en un momento determinado, nos decía: «Disculpadme unos minutos que voy a escribirme el artículo». Y se metía en un cuarto con una Olivetti portátil y todos escuchábamos el tecleo rapidísimo. Aquello era impresionante"13.

Conchita Bermejo ha visto a Jaime escribirse el artículo en veinte minutos. «Yo ya lo tengo en la cabeza», le decía Campmany a su esposa. También le dijo que si él hubiera sido atleta "habría recorrido nada más que los cien metros lisos, que era para lo que servía, porque para los libros más largos él era muy crítico consigo mismo” ${ }^{14}$. Campmany se refería a su capacidad para el artículo periodístico, para esa literatura urgente que luego deviene en un periodismo sosegado.

13 Entrevista con Díez de Revenga en marzo de 2014.

14 Entrevista con Conchita Bermejo en mayo de 2014. 
Precisamente, Campmany había dejado escrito en un artículo literario para el semanario Juventud, en 1953, esta misma idea del acto de escribir presurosamente y con la consecuencia "despaciosa" de lo escrito: "Uno ve y oye y huele lo que ocurre, milagrosamente, en el alrededor y lo escribe sin fuerza apenas para detenerse a descansar. La prosa después resulta lenta y despaciosa, como si se hubiera ido vertiendo de una manera dulce y frutal". Una sugestiva y lírica definición del periodismo literario.

\subsection{La expulsión de Arriba y el canto a la libertad}

A partir del año 1970, las 'Pajaritas' se publican intermitentemente hasta junio de 1971. El motivo: Campmany había sido nombrado director del Arriba y acaso la ocupación le restara tiempo para el artículo diario. En la toma de posesión del nuevo cargo el 22 de abril de 1970 Campmany expresó su propósito de hacer un periódico para todos, "sin excluir a nadie" (Arriba, 23/04/1970). Sin embargo, aquella buena intención no duró mucho. El propio Campmany contó que había sido llamado a dirigir aquel periódico "con el encargo de abrir sus páginas a la discrepancia política, preparar el entierro de fórmulas pasadas y ya inviables, y allanar poco a poco el camino hacia la democracia. Pero ya digo que la primavera duró poco. (...) Al año de mi toma de posesión fui expulsado de la dirección de Arriba (1997: 21).

Como señala Juan Cantavella, las presiones que estaba recibiendo Campmany “le impulsaron a buscar la retirada” porque "se dio cuenta en un momento determinado de que encontraba demasiadas dificultades para llevar a cabo lo que quería, a causa del ambiente cerrado en el que se desarrollaba su trabajo, y eso no era bueno para la columna” (2012: 78).

En agosto de 1971, dos meses después de aquella expulsión, Campmany dio el pregón en el XI Festival del Cante de las Minas con un discurso del que, por su tono y por lo que expresa, podemos extraer nuestras propias conclusiones y alegorías que estriban en su insistente querencia por el cante jondo a la libertad periodística: "En Cartagena hay un penal y allí también se canta. En el penal se canta como solo cantan los pájaros cautivos. Lo que más duele en el alma, no es el amor, lo que más duele en el alma, amigos, es una cosa que se llama libertad"15.

15 El pregón se recoge en el libro Pregones del festival del cante de las minas (La Unión), a cargo de César Oliva (1997: 31-37). 
Cuadro 2. Viñeta que recrea a Campmany subido a lomos de su célebre ‘Pajarita'

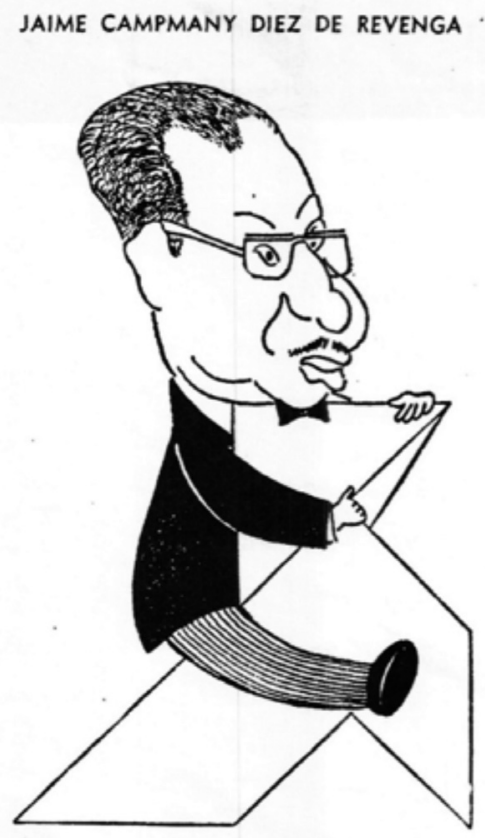

Fuente: Molin. Hoja del Lunes de Murcia, el 27 de noviembre de 1978, p. 3.

\section{Conclusiones}

- $\quad$ Las 'Pajaritas de papel' de Campmany poseen gran valor como piezas periodísticas y literarias, de modo que podemos adjetivar a estos artículos como auténticas joyas del periodismo literario de la segunda mitad del siglo XX. En ellos, Campmany reivindica la necesidad de un nuevo periodismo basado en la sinceridad, en el contraste de opiniones y en un lenguaje sencillo, claro y literario, para una España de cambios y de libertades que se hallaba en el horizonte.

- La escritura de estos textos representa el eslabón que recupera y actualiza la tradición del periodismo literario español y lo une a las nuevas demandas del periodismo de opinión: el de la columna moderna que vivirá su edad dorada en años 70 y 80 del siglo XX. Por tanto afirmamos que las 'Pajaritas', de una exquisitez y calidad literaria sobresaliente, son un antecedente preclaro del columnismo posterior. 
- L L L L tres pilares sobre los que se sostienen las 'Pajaritas' -viveza, ternura e ironía- influirán también en la obra periodística posterior de Campmany como columnista que se caracterizará precisamente por su humanidad, por su ternura, por su humor y por su socarronería satírica.

- $\quad$ En cuanto a la tipología que aporta este trabajo a la hora de clasificar las 'Pajaritas', cabe señalar que, en primer lugar, por las características formales, se insertan en la modalidad de la columna-microrrelato y la columna-poema; y en cuanto a la temática, los artículos oscilan entre lo reivindicativo, lo nostálgico y la recreación de sucesos.

- $\quad$ Este trabajo invita a la investigación sobre otros periodistas literarios que por aquellos años sesenta reivindicaban un periodismo libre para una España democrática. El momento histórico y el ambiente del periodismo en aquel tiempo hace muy sugestiva la profundización en este tema de estudio.

En definitiva, este trabajo aporta a la disciplina que estudia las relaciones entre el Periodismo y la Literatura un modelo original de artículos literarios como fueron las 'Pajaritas de papel', que resultan útiles para la investigación del periodismo de aquellos años y para comprender con mayor claridad aquel período de la historia de España.

\section{Referencias bibliográficas}

Anónimo (1945): “Rasgos del poeta Jaime Campmany y Díez de Revenga”, La Verdad, 20 de diciembre, p. 3.

Anónimo (1947): “Salvador Jiménez y Jaime Campmany, premiados en Cádiz”, Línea, 1 de mayo, p. 8.

Anónimo (1970): “Toma posesión el nuevo director de «Arriba»", Arriba, 23 de abril, p. 8.

Arco, A. (1995): “Las cartas boca arriba”, La Verdad, 12 de noviembre, p. 6.

Ballester, J. (1947): “La séptima entrega de Azarbe”, La Verdad, 19 de julio, p. 3.

Campmany, J. (1967a): “La pajarita de papel”. Suplemento “Murcia Documento’. Línea, 5 de noviembre, pp. 21-24.

- (1953): “La noche de San Juan”, Juventud, 21 de junio al 1 de julio.

- (1966a): "Hablar", Arriba, 4 de octubre

- (1966b): “Pajaritas de papel”, Arriba, 9 de junio.

- (1967b): "Llanto", Arriba, 13 de enero.

- (1967c): "Razón de amor”, Arriba, 27 de mayo.

- (1967d): “El perfil amable”, Arriba, 14 de agosto.

- (1967e): "Alpiste para la pajarita”, Arriba, 19 de octubre. 
- (1971): “Pregón del XI Festival Nacional del Cante de las Minas (1971)”, en Oliva, C. (Coord.) (1997): Pregones del festival del cante de las minas (La Unión). Murcia: Servicio de Publicaciones. Universidad de Murcia, pp. 31-37.

- (1992): Cartas batuecas: correo a políticos y otros notables del Reino. Madrid: Ediciones Temas de Hoy

- (1997): Doy mi palabra. Mis 100 mejores artículos. Madrid: Espasa.

Cano, M. (2004): "No me arrepiento de una sola de las palabras que he escrito en mi vida", El Faro de Murcia, 13 de octubre, pp. 7-12.

Cantavella, J. (2011): “La columna en verso: recuerdo y presencia de poetas y versificadores”, Doxa Comunicación, n. 13, pp. 67-68. URL: http://dspace.ceu.es/bitstream/10637/5847/1/n\%C2\%BA\%20XIII_pp67_88.pdf [Consultado el 27/02/2017].

Delibes, M. (2010): Obras completas VI. El periodista. El ensayista. Barcelona: Ediciones Destino.

Díez de Revenga, F. J. (2005): Azarbe (1946-1948). Murcia: Real Academia Alfonso X El Sabio.

Fernández, A. (2014a): “Entrevista a Conchita Bermejo”, en Fernández, A. (2017): El periodismo literario de Jaime Campmany. Tesis Doctoral. Universidad de Murcia.

- (2014b): “Entrevista a Emilio Campmany", en Fernández, A. (2017): El periodismo literario de Jaime Campmany. Tesis Doctoral. Universidad de Murcia.

- (2014c): "Entrevista a Francisco Javier Díez de Revenga”, en Fernández, A. (2017): El periodismo literario de Jaime Campmany. Tesis Doctoral. Universidad de Murcia.

- (2017): El periodismo literario de Jaime Campmany. Tesis Doctoral. Universidad de Murcia.

Galiana, I. (1967): “Jaime Campmany o un tren en el que nunca viajó", Línea, 29 de enero, pp. 28-29.

H.H, M. (1997): "Entrevista al periodista y escritor Jaime Campmany, director de la revista EPOCA", De la noche al día. Radio 1, 7 de abril. Centro RNE. Duración total: 00: 23: 05.000. REF: P0018909.

León Gross, T. (2010): “La retórica del articulismo periodístico-literario”, en Angulo, M. y Rodríguez, J.M. (coords.): Periodismo literario. Naturaleza, antecedentes, paradigmas y perspectivas. Madrid: Editorial Fragua, pp.117-140.

López Pan, F. y Gómez Baceiredo, B. (2010): “El Periodismo literario como sala de espera de la literatura”, en Angulo, M. y Rodríguez, J.M. (coords.): Periodismo literario. Naturaleza, antecedentes, paradigmas y perspectivas. Madrid: Editorial Fragua, pp. 21-40.

López, A. (2012): La columna. Periodismo y literatura en un género plural. Zamora: Comunicación Social Ediciones y Publicaciones.

López, P. (2012): “La 'Ley Fraga': luces y sombras”, 233grados.com, 16 de enero. URL: http://233grados.lainformacion.com/ blog/2012/01/la-ley-fraga-luces-y-sombras.html [Consultado el 5 de abril de 2017]. 
Perlado, J. J. (2007): El artículo literario y periodístico. Paisajes y Personajes. Madrid: Eiunsa.

Pizarroso, A. (1992): De la Gazeta Nueva a Canal Plus. Breve historia de los medios de comunicación en España. Madrid: Edit. Complutense.

Real Academia Española (2015): “Sinceridad", en Diccionario de la lengua española (23. a ed.). Recuperado de http://dle.rae.es/?id=XwnKRc7 [Consultado el 05/04/2017].

Ruiz de la Cierva, M. D. C. (2012): “Interdiscursividad entre literatura y periodismo: la columna”, Proceeding of the 10th World Congress of the International Association for Semiotic Studes (IASS/AIS). Universidad de Coruña, pp. 1735-1748. URL: http://ruc.udc.es/dspace/handle/2183/13471 [Consultado el 27/02/2017].

Umbral, F. (2001): “Jaime Campmany”, El Cultural, 28 de febrero. URL: http://www.elcultural.com/revista/letras/JaimeCampmany/2966 [Consultado el 05/04/2017].

Vela, D. (2009): “Años sesenta: Balbuceos de libertad de prensa”, en Gutiérrez, J. (coord.): De Azorín a Umbral. Un siglo de periodismo literario español. La Coruña: Netbiblo, pp. 620-688.

- (2009): “La década del cambio: Cinco años para finalizar, cinco años para empezar”, en Gutiérrez, J. (coord.): De Azorín a Umbral. Un siglo de periodismo literario español. La Coruña: Netbiblo, pp. 689-777. 